\title{
Proton transfers in the Strecker reaction revealed by DFT calculations
}

\author{
Shinichi Yamabe*, Guixiang Zeng, Wei Guan and Shigeyoshi Sakaki
}

\author{
Full Research Paper \\ Address: \\ Fukui Institute for Fundamental Chemistry, Kyoto University, \\ Takano-Nishihiraki-cho 34-4, Sakyo-ku, Kyoto 606-8103, JAPAN. \\ Phone: +81-075-711-7907 \\ Email: \\ Shinichi Yamabe* - yamabes@fukui.kyoto-u.ac.jp \\ * Corresponding author \\ Keywords: \\ amide intermediate; DFT calculations; hydrogen bonds; Strecker \\ reaction; transition state
}

Beilstein J. Org. Chem. 2014, 10, 1765-1774.

doi:10.3762/bjoc. 10.184

Received: 20 March 2014

Accepted: 05 July 2014

Published: 01 August 2014

Associate Editor: J. A. Murphy

(C) 2014 Yamabe et al; licensee Beilstein-Institut.

License and terms: see end of document.

\begin{abstract}
The Strecker reaction of acetaldehyde, $\mathrm{NH}_{3}$, and $\mathrm{HCN}$ to afford alanine was studied by DFT calculations for the first time, which involves two reaction stages. In the first reaction stage, the aminonitrile was formed. The rate-determining step is the deprotonation of the $\mathrm{NH}_{3}{ }^{+}$group in $\mathrm{MeCH}(\mathrm{OH})-\mathrm{NH}_{3}{ }^{+}$to form 1-aminoethanol, which occurs with an activation energy barrier $\left(\Delta E^{\ddagger}\right)$ of $9.6 \mathrm{kcal} /$ mol. The stereochemistry ( $R$ or $S$ ) of the aminonitrile product is determined at the $\mathrm{NH}_{3}$ addition step to the carbonyl carbon of the aldehyde. While the addition of $\mathrm{CN}^{-}$to the carbon atom of the protonated imine 7 appears to scramble the stereochemistry, the water cluster above the imine plane reinforces the $\mathrm{CN}^{-}$to attack the imine group below the plane. The enforcement hinders the scrambling. In the second stage, the aminonitrile transforms to alanine, where an amide $\mathrm{Me}-\mathrm{CH}\left(\mathrm{NH}_{2}\right)-\mathrm{C}(=\mathrm{O})-\mathrm{NH}_{2}$ is the key intermediate. The rate-determining step is the hydrolysis of the cyano group of N(amino)-protonated aminonitrile which occurs with an $\Delta E^{\ddagger}$ value of $34.7 \mathrm{kcal} / \mathrm{mol}$. In the Strecker reaction, the proton transfer along the hydrogen bonds plays a crucial role.
\end{abstract}

\section{Introduction}

In 1850, Adolph Strecker reported a reaction that affords alanine from acetaldehyde, ammonia and hydrogen cyanide [1]. The original form of Strecker amino acid synthesis is shown in Scheme 1(a). In this reaction, the aldehyde reacts with hydrogen cyanide to form an aminonitrile, which undergoes hydrolysis to afford alanine in the acidic solution. The traditional Strecker reaction gave racemic $\alpha$-aminonitriles (mixtures of equal amounts of $R$ and $S$ forms), where an imine $\mathrm{RCH}=\mathrm{NH}$ was considered to be the key intermediate [2]. Three typical reactions are presented in Scheme 1(b) [3].

In 1963, Harada reported the first asymmetric Strecker reaction, in which an (S)- $\alpha$-phenylethylamine was employed as the chiral auxiliary [4]. In this reaction, he obtained a chiral alanine with 95\% optically activity; see Scheme 2 . In 1996, Lipton et al. succeeded in a series of asymmetric Strecker reactions by 


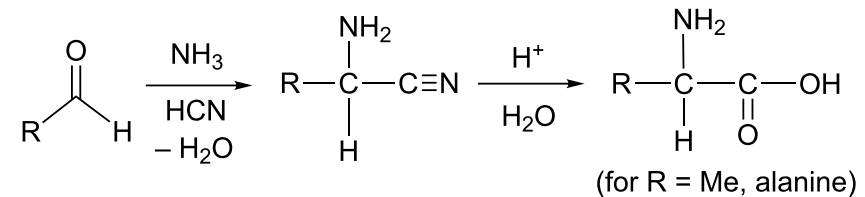

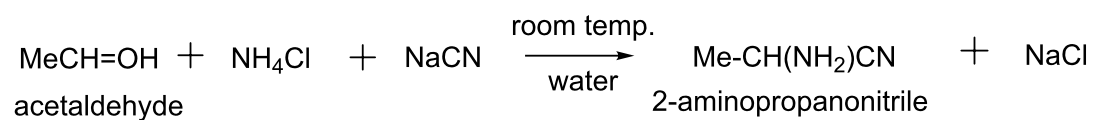

$$
\begin{aligned}
& \mathrm{Me}-\mathrm{CH}\left(\mathrm{NH}_{2}\right) \mathrm{CN}+2 \mathrm{H}_{2} \mathrm{O}+2 \mathrm{HCl} \stackrel{\Delta}{\longrightarrow} \begin{array}{c}
\mathrm{Me}-\mathrm{CH}\left(\mathrm{NH}_{3} \mathrm{Cl}\right) \mathrm{COOH} \\
\text { alanine hydrochloride }
\end{array}+\mathrm{NH}_{4} \mathrm{Cl} \\
& 2 \mathrm{Me}-\mathrm{CH}\left(\mathrm{NH}_{3} \mathrm{Cl}\right) \mathrm{COOH}+\mathrm{Pb}(\mathrm{OH})_{2} \underset{\text { water }}{\stackrel{\Delta}{\longrightarrow}} 2 \mathrm{Me}-\mathrm{CH}\left(\mathrm{NH}_{2}\right) \mathrm{COOH}+\mathrm{PbCl}_{2}
\end{aligned}
$$

Scheme 1: The general form of the Strecker reaction. The reaction (b) is taken from [2].

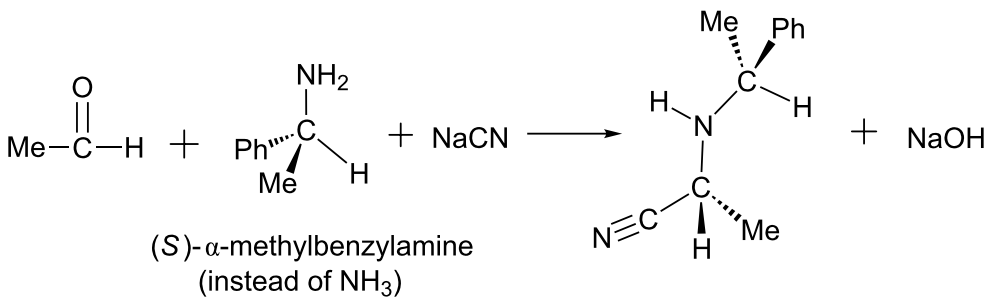

$\mathrm{HCl}$ in $\mathrm{H}_{2} \mathrm{O}$ then hydrogenosis<smiles>C[C@H](N)C(=O)O</smiles>

$(R)$-alanine

Scheme 2: The first asymmetric Strecker reaction [4]

employing a chiral catalyst, a cyclic dipeptide [5]. In these reactions, N-substituted imines react with $\mathrm{HCN}$ to yield (S)- $\alpha$ aminonitriles with remarkably high enantiomeric excess (ee). One example is shown in Scheme 3.
However, when benzaldehyde and $\mathrm{NH}_{3}$ instead of the N-substituted imine were employed as the substrates, the reaction afforded an initial product $\mathrm{Ph}-\mathrm{CH}\left(\mathrm{NH}_{2}\right)-\mathrm{CN}$ of configurational instability[5]. In the following, Sigman and Jacobsen used a<smiles>[R]N=Cc1ccccc1</smiles><smiles>[R]N[C@H](C#N)c1ccccc1</smiles>

N-substituted-imine

(S)- $\alpha$-(N-substituted)-aminonitrile

$$
\left[\mathrm{R}=\mathrm{Ph}_{2} \mathrm{CH} \text { yield } 95 \%\right.
$$


parallel combinatorial library synthesis for the discovery and optimization of a chiral catalyst for the reaction of imines and HCN [6]. From then on, various catalytic asymmetric Strecker reactions have been reported to gain high enantioselectivity of the hydrocyanation reaction of imines [7-12]. However, the origin of the enantioselectivity in the asymmetric Strecker reactions has not been clarified.

To our knowledge, the elementary processes of the whole Strecker reaction have not been elucidated. As shown in Scheme 1, the Strecker reaction includes two reaction stages. The first reaction stage is the condensation of aldehydes with ammonia and hydrogen cyanide leading to $\alpha$-aminonitriles. The second reaction stage is the hydrolysis of the nitrile group. In these reactions, $\mathrm{K}^{+}$(or $\mathrm{Na}^{+}$) and $\mathrm{Cl}^{-}$ions are not involved, as shown in Scheme 1(a). Therefore, it is suitable to the theoretical investigation of the reaction mechanism, because the effect of counter ions does not need to be considered.

Actually, several theoretical studies were reported of the last step of the first reaction stage of the Strecker reaction [10-16], i.e. the hydrocyanation of imines (or protonated imines $+\mathrm{CN}^{-}$) to aminonitriles. In those works, how the nucleophile $\mathrm{CN}^{-}$is generated has not been examined. Because $\mathrm{HCN}$ is a very weak acid with a dissociation constant of $K_{\mathrm{a}}=1.3 \times 10^{-9} \mathrm{~mol} / \mathrm{L}$ (in water, $18{ }^{\circ} \mathrm{C}$ ), direct dissociation reaction $\mathrm{HCN} \rightarrow \mathrm{H}^{+}+\mathrm{CN}^{-}$is difficult to occur.

In the second reaction stage, i.e., the acid-catalyzed hydrolysis of the cyano group, protonation of the group appears to cause the addition of $\mathrm{OH}_{2}$ to the cyano carbon:

$$
\begin{aligned}
& \mathrm{R}-\mathrm{CH}\left(\mathrm{NH}_{2}\right)-\mathrm{CN}+\mathrm{H}^{+} \rightarrow \mathrm{R}-\mathrm{CH}\left(\mathrm{NH}_{2}\right)-\mathrm{CNH}^{+} \\
& \mathrm{R}-\mathrm{CH}\left(\mathrm{NH}_{2}\right)-\mathrm{CNH}^{+}+\mathrm{OH}_{2} \rightarrow \mathrm{R}-\mathrm{CH}\left(\mathrm{NH}_{2}\right)-\mathrm{C}(\mathrm{OH})=\mathrm{NH}+\mathrm{H}^{+}
\end{aligned}
$$

However, the proton affinity (PA) of the nitrile is much smaller than that of the amino group, for example, the PAs of the cyano and amino groups of 2-amino-propanonitrile (Me- $\mathrm{CH}\left(\mathrm{NH}_{2}\right)$ $\mathrm{CN})$ are 190.7 and $199.6 \mathrm{kcal} / \mathrm{mol}$, respectively. Thus, in the acidic solution $\left(2 \mathrm{H}_{2} \mathrm{O}+2 \mathrm{HCl}\right)$, $\mathrm{Me}-\mathrm{CH}\left(\mathrm{NH}_{3}{ }^{+}\right)-\mathrm{CN}$ should be afforded; see Scheme 1(b). The reaction mechanism of this hydrolysis is also unclear.

To address the above issues, we performed DFT calculations of the Strecker reaction shown in Scheme 1(a). Here, ten specific water molecules were considered.

\section{Methods of calculation}

Geometry optimizations were performed by density functional theory (DFT) with the B3LYP $[17,18]$ functional. The basis set
$6-311+G(d, p)$ was employed for all the atoms in the calculations. The solution (water) effect was considered by the Polarizable Continuum Model (PCM) [19-21]. Vibrational analyses were carried out to make sure whether a stationary point is an equilibrium structure or a transition state (TS). From TSs, reaction paths were traced by the intrinsic reaction coordinate (IRC) method [22,23] to obtain the energy-minimum geometries. All the calculations were carried out using the GAUSSIAN 09 [24] program package. Throughout this paper, the discussion was presented based on the potential energy changes with zero-point vibrational energy (ZPE) correction unless otherwise noted.

\section{Results and Discussion Formation reaction of aminonitrile (the first stage)}

The reaction model is shown in Scheme 4. In the model, lonepair electrons of the oxygen and nitrogen atoms participate in hydrogen bonds. In calculating each TS, ten water molecules were placed so that the large hydrogen-bond stabilization is gained. After geometries of TSs were determined, those of energy minima were obtained by IRC and the subsequent optimizations. By the use of the similar water cluster models, TS geometries and activation energies $\left(E_{\mathrm{a}}{ }^{\prime} \mathrm{s}\right)$ in the base promoted ester hydrolyses were calculated [25]. In $\mathrm{Ph}-\mathrm{COOE}_{\mathrm{t}}+$ $\mathrm{OH}^{-}\left(\mathrm{H}_{2} \mathrm{O}\right)_{n} \rightarrow \mathrm{Ph}-\mathrm{COO}^{-}+\mathrm{HO}-\mathrm{E}_{\mathrm{t}}+\left(\mathrm{H}_{2} \mathrm{O}\right)_{n}, E_{\mathrm{a}}=+14.7 \mathrm{kcal} /$ $\operatorname{mol}(n=5),+16.3(n=8),+16.3(n=12)$ and $+15.6(n=16)$ were obtained, where the experimental $E_{\mathrm{a}}$ is $+14.6 \mathrm{kcal} / \mathrm{mol}$. Also, in the Bamberger rearrangement $\mathrm{Ph}-\mathrm{NH}(\mathrm{OH})+$ $\left(\mathrm{H}_{3} \mathrm{O}^{+}\right)_{2}\left(\mathrm{H}_{2} \mathrm{O}\right)_{13} \rightarrow$ para-HO- $\mathrm{C}_{6} \mathrm{H}_{4}-\mathrm{NH}_{3}{ }^{+}+\mathrm{H}_{3} \mathrm{O}^{+}\left(\mathrm{H}_{2} \mathrm{O}\right)_{14}$ [26], $E_{\mathrm{a}}=+26.3 \mathrm{kcal} / \mathrm{mol}$ was calculated, where the experimental $E_{\mathrm{a}}$ is $+24.8 \mathrm{kcal} / \mathrm{mol}$.

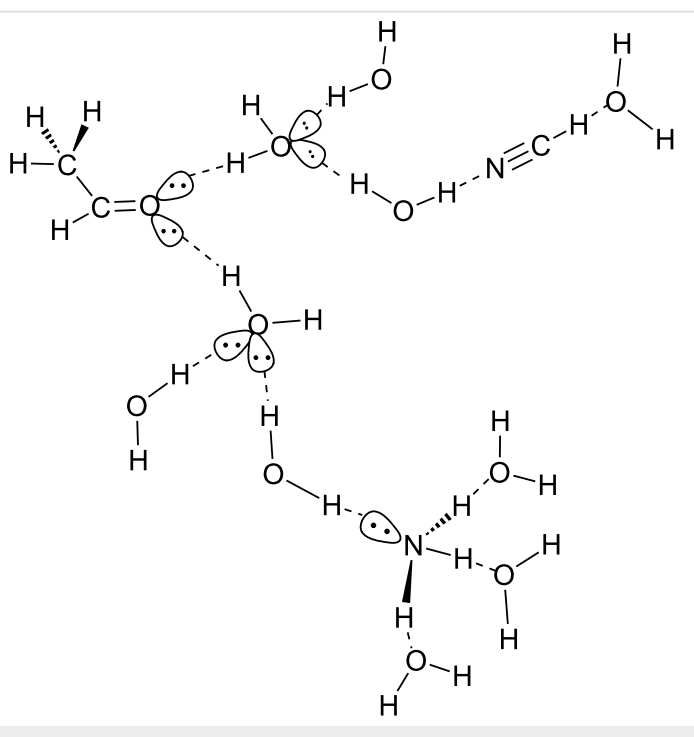

Scheme 4: A reaction model composed of $\mathrm{Me}-\mathrm{CH}=\mathrm{O}, \mathrm{HCN}, \mathrm{NH}_{3}$ and $\left(\mathrm{H}_{2} \mathrm{O}\right)_{10}$ for geometry optimizations to trace elementary processes. Broken lines stand for hydrogen bonds. 


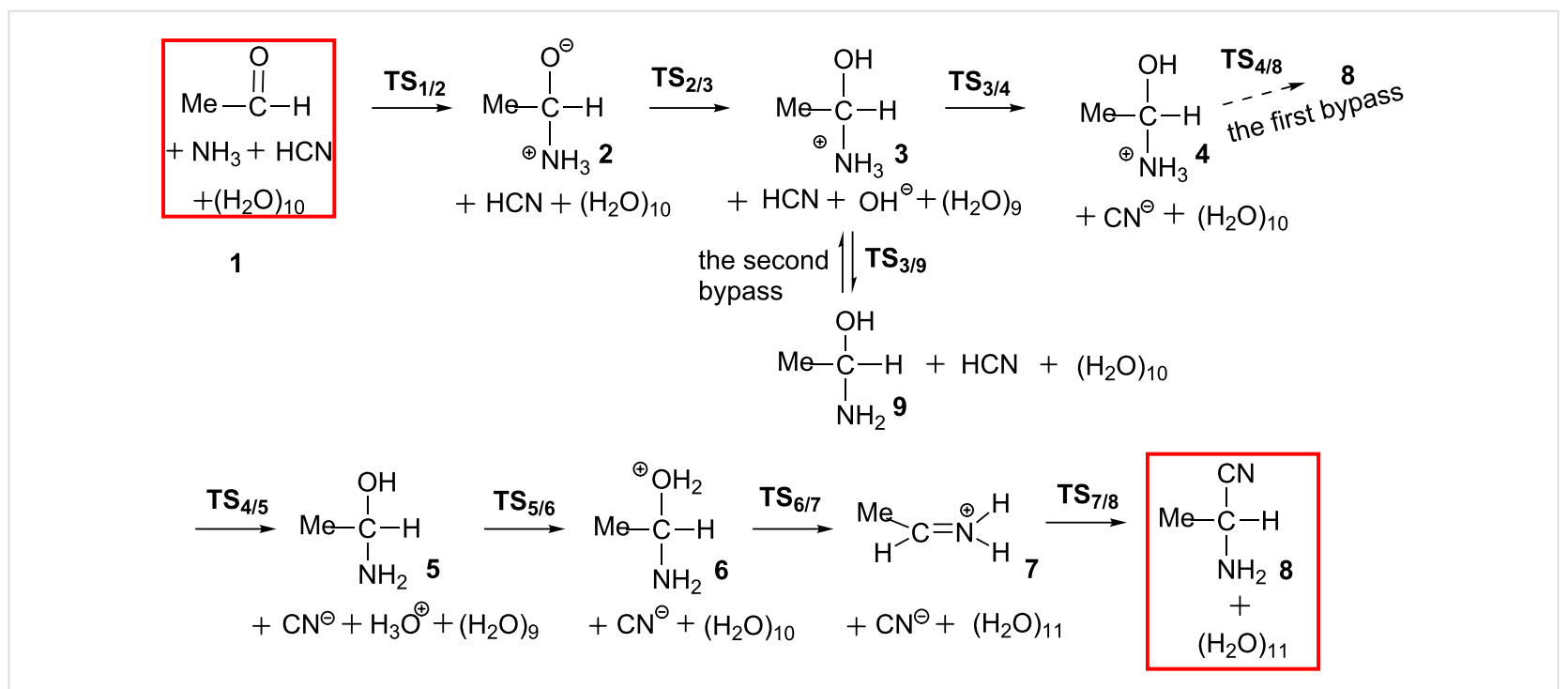

Scheme 5: Possible pathways for the formation of aminonitrile from acetaldehyde.

Our proposed reaction pathways are shown in Scheme 5. Geometries of TSs are shown in Figure 1 and those of precursor $\mathbf{1}$, intermediates and product $\mathbf{8}$ are provided in Supporting Information File 1 Figure S1.

As shown in Figure S1, Supporting Information File 1, $\mathrm{MeCH}=\mathrm{O}, \mathrm{NH}_{3}$ and $\mathrm{HCN}$ are separated by the $\mathrm{H}_{2} \mathrm{O}$ cluster in the precursor complex 1 . The reaction begins with the addition of $\mathrm{NH}_{3}$ to the carbonyl carbon of acetaldehyde to form a Mulliken charge-transfer complex 2 . This complex was firstly proposed here. In 2, the $\mathrm{C}-\mathrm{O}$ bond is elongated to1.345 $\AA$, which has an alkoxide character and the complex is not stable in the gas phase. However, it is more stable than the precursor complex by $3.5 \mathrm{kcal} / \mathrm{mol}$ when ten specific water molecules are considered; see Figure 2. This result indicates that the consideration of water molecules in the reaction is necessary to describe the step $\mathbf{1} \rightarrow \mathbf{2}$. Then, the alkoxide oxygen atom captures a proton from a surrounding water molecule to form $\mathrm{Me}(\mathrm{H}) \mathrm{C}(\mathrm{OH})-\mathrm{NH}_{3}{ }^{+}$and a remaining $\mathrm{OH}^{-}$anion in the surrounding. They form an ion pair $3 \mathrm{Me}(\mathrm{H}) \mathrm{C}(\mathrm{OH})-\mathrm{NH}_{3}{ }^{+}$and $\mathrm{OH}^{-}$]. Next, the hydroxide ion catches a proton from $\mathrm{HCN}$ through the transition state $\mathbf{T S}_{\mathbf{3} / \mathbf{4}}$ to afford a more stable ionpair intermediate $4\left[\mathrm{Me}(\mathrm{H}) \mathrm{C}(\mathrm{OH})-\mathrm{NH}_{3}{ }^{+}\right.$and $\left.\mathrm{CN}^{-}\right]$. This step is exothermic by $5.5 \mathrm{kcal} / \mathrm{mol}$ with a small activation energy barrier $\left(\Delta E^{\ddagger}\right)$ of $1.4 \mathrm{kcal} / \mathrm{mol}$. Starting from 4 , a proton of the $\mathrm{NH}_{3}{ }^{+}$group migrates to one water molecule to form 5 $\left[\mathrm{Me}(\mathrm{H}) \mathrm{C}(\mathrm{OH})-\mathrm{NH}_{2}\left(\mathrm{H}_{3} \mathrm{O}^{+}\right)\right.$and $\left.\mathrm{CN}^{-}\right]$via a transition state $\mathbf{T S}_{\mathbf{4} / 5}$. After that, the proton migrates from $\mathrm{H}_{3} \mathrm{O}^{+}$to the hydroxy group of $\mathrm{Me}(\mathrm{H}) \mathrm{C}(\mathrm{OH})-\mathrm{NH}_{2}$ via $\mathbf{T S}_{\mathbf{5} / \mathbf{6}}$ to yield $\mathrm{Me}(\mathrm{H}) \mathrm{C}\left(\mathrm{OH}_{2}{ }^{+}\right)-$ $\mathrm{NH}_{2}$ 6. From $\mathbf{6}, \mathrm{H}_{2} \mathrm{O}$ is easily eliminated through $\mathbf{T S}_{\mathbf{6} / 7}$ to afford the protonated imine 7 with a $\Delta E^{\neq}$value of $0.3 \mathrm{kcal} / \mathrm{mol}$. At last, $\mathrm{CN}^{-}$nucleophilically attacks the carbon atom of
$\mathrm{MeCH}=\mathrm{NH}_{2}{ }^{+}$through $\mathbf{T S}_{7 / 8}$ to afford a 2-aminopropanonitrile 8.

Starting from 4 , a concerted $\mathrm{S}_{\mathrm{N}}$ 2-type pathway was also examined, which directly leads to the nitrile compound $\mathbf{8}$; see Scheme 6. In this pathway, the proton is transferred from the $\mathrm{NH}_{3}{ }^{+}$group to the hydroxy group via a two-water-molecule bridge. At the same time, the $\mathrm{H}_{2} \mathrm{O}$ elimination and the approach of $\mathrm{CN}^{-}$to $\mathbf{4}$ concomitantly take place with a Walden inversion. The transition state $\mathbf{T S}_{\mathbf{4 / 8}}$ was successfully located; see Figure 1. However, this pathway needs a large energy barrier of $58.8=[+51.3-(-7.5)] \mathrm{kcal} / \mathrm{mol}$, indicating that it is difficult to occur.

Starting from the ion-pair intermediate $\mathbf{3}$, we also investigated the possibility that the hydroxide ion captures a proton from the $\mathrm{NH}_{3}{ }^{+}$group to form 9, Me-C(H)(OH)- $\mathrm{NH}_{3}{ }^{+}+\mathrm{OH}^{-} \rightarrow$ Me- $\mathrm{C}(\mathrm{H})(\mathrm{OH})-\mathrm{NH}_{2}+\mathrm{OH}_{2}$. This reaction step occurs through a transition state $\mathbf{T S}_{\mathbf{3} / \mathbf{9}}$ with a $\Delta E^{+}$value of $1.9 \mathrm{kcal} / \mathrm{mol}$, which is comparable to that $(1.4 \mathrm{kcal} / \mathrm{mol})$ of the proton transfer step

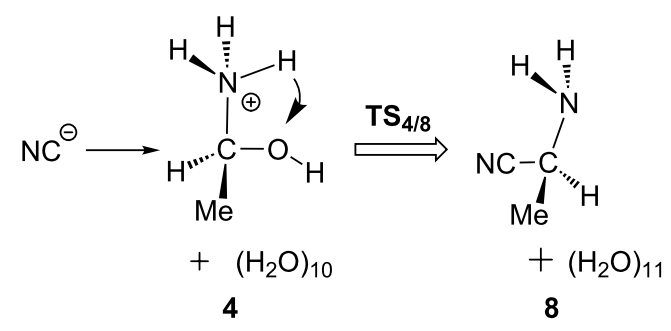

Scheme 6: A short-cut path by the nucleophilic displacement and the concomitant proton transfer. "The first bypass" in Scheme 5. 

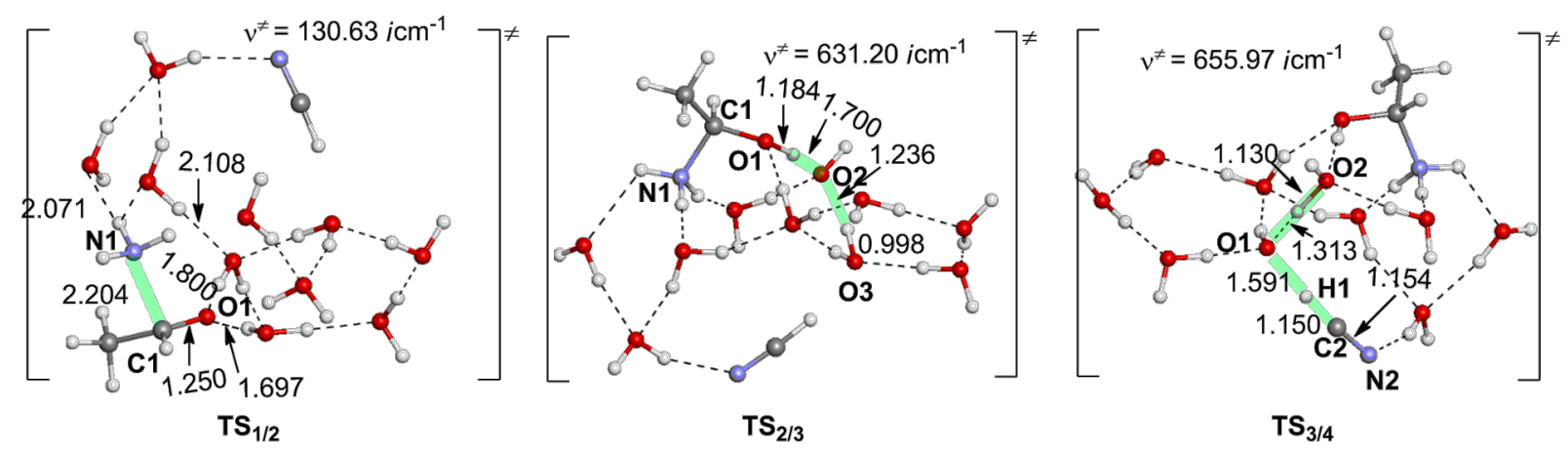

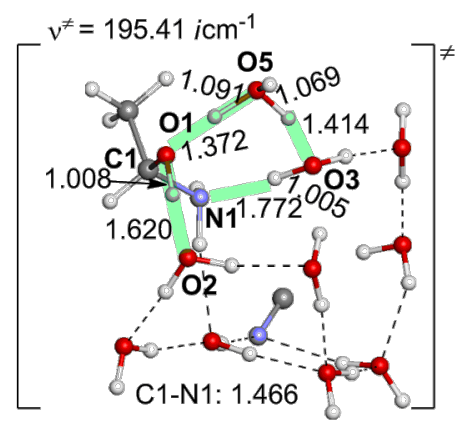

$\mathrm{TS}_{4 / 5}$

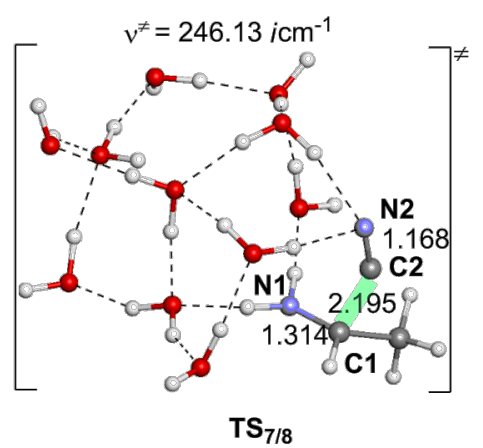

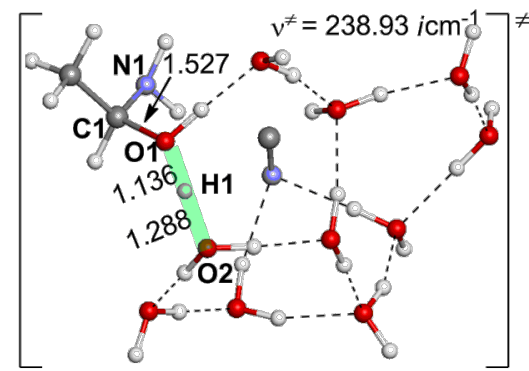

$\mathrm{TS}_{5 / 6}$

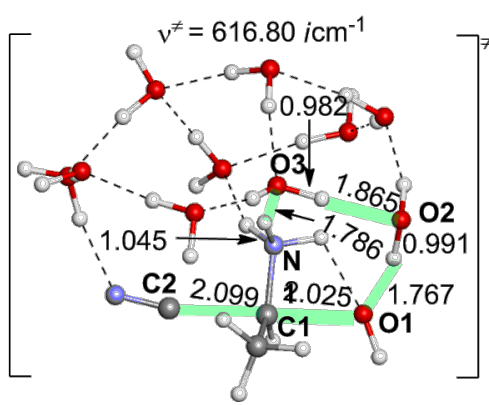

$\mathrm{TS}_{4 / 8}$

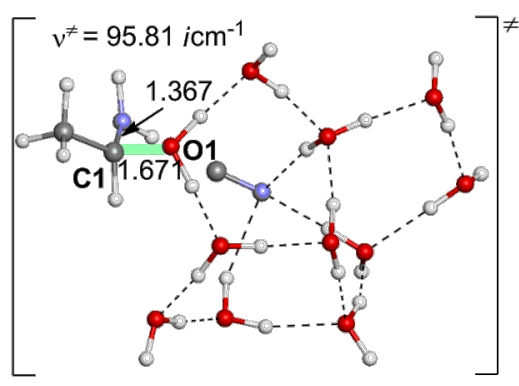

$\mathrm{TS}_{6 / 7}$

Figure 1: Geometries of transition states along the reaction from acetaldehyde (1) to the aminonitrile 8. Distances are in $\AA$. TS ${ }_{1 / 2}$ means, for instance, a transition state for the step $\mathbf{1} \rightarrow \mathbf{2}$.

from $\mathrm{HCN}$ to $\mathrm{OH}^{-}$. However, 9 is less stable than $\mathbf{4}$ by $1.8 \mathrm{kcal} /$ mol, indicating that the $\mathrm{OH}^{-}$prefers to capture a proton from $\mathrm{HCN}$ rather than from the $\mathrm{NH}_{3}{ }^{+}$group.

As shown in Figure 2, the rate-determining step of this reaction stage is the proton migration from the $\mathrm{NH}_{3}{ }^{+}$group to the water cluster (from 4 to 5), where the energy barrier is $17.1=[+9.6-$ $(-7.5)] \mathrm{kcal} / \mathrm{mol}$. Other proton transfer steps facilely occur. These results are in consistent with the room-temperature experimental condition in Scheme 1. For the rate-determining step, we also checked an extended model "TS $\mathbf{T}_{\mathbf{4} / \mathbf{5}} \mathbf{-} \mathbf{e x t}$ ", where ten water molecules are added (the molecular formula, $\mathrm{C}_{3} \mathrm{H}_{48} \mathrm{~N}_{2} \mathrm{O}_{21}$ ). The geometry of $\mathbf{T S}_{4 / 5}$-ext is shown in
Supporting Information File 1 Figure S2. The geometrical parameters of the proton-transfer region of $\mathbf{T S}_{\mathbf{4} / \mathbf{5}^{-}} \mathbf{e x t}$ are similar to that of $\mathbf{T S}_{\mathbf{4} / \mathbf{5}}$. Also, the energy difference between $\mathbf{T S}_{\mathbf{4} / \mathbf{5}} \mathbf{- e x t}$ and $4-\operatorname{ext}(17.3 \mathrm{kcal} / \mathrm{mol})$ is very close to that $(17.1 \mathrm{kcal} / \mathrm{mol})$ between $\mathbf{T S}_{\mathbf{4} / \mathbf{5}}$ and $\mathbf{4}$.

As shown in Figure 1, the product, aminonitrile 8, is in an $S$ form. However, racemic $\alpha$-aminonitriles are obtained experimentally. This stereochemical scrambling is explicable on the basis of the computational results, as follows. In $\mathbf{T S}_{\mathbf{1} / 2}$, the $\mathrm{NH}_{3}$ molecule may add to $\mathrm{MeCH}=\mathrm{O}$ from both upper and lower directions equivalently, which leads to the racemic products. However, in $\mathbf{T S}_{\mathbf{7 / 8}}$, the nucleophile $\mathrm{CN}^{-}$is obligated to attack 


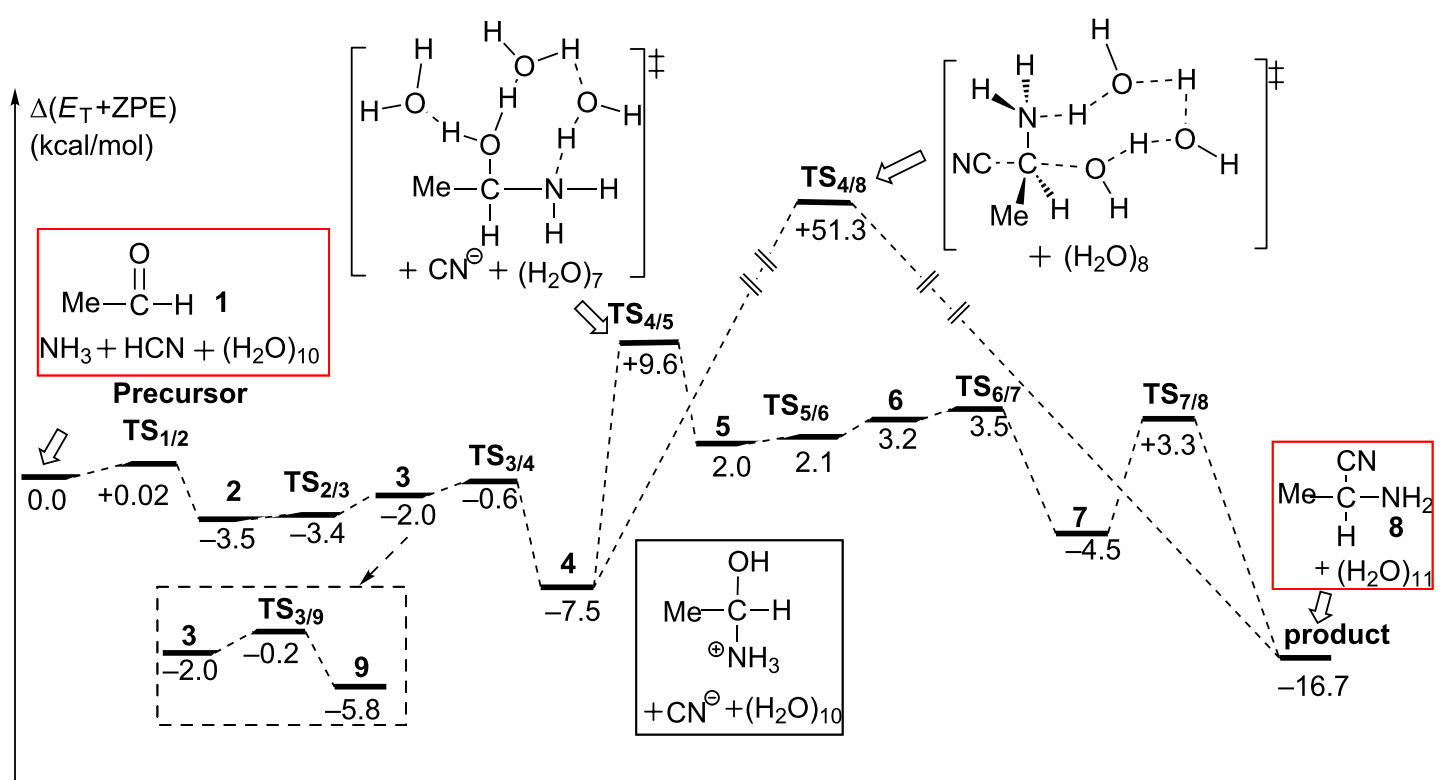

Figure 2: Energy changes along elementary processes from acetaldehyde to aminonitrile. Bold numbers are defined in Scheme 5.

$\mathrm{MeC}(\mathrm{H})=\mathrm{NH}_{2}{ }^{+}$at the plane opposite to the $\mathrm{OH}_{2}$ dissociating side (see Scheme 7). The addition model of $\mathbf{T S}_{\mathbf{1 / 2}}$ was examined by the use of the amine in Scheme 2 . The activation energy of the less crowded $\mathbf{T S}_{\mathbf{1 / 2}} \mathbf{-} \mathbf{A}$ is $1.8 \mathrm{kcal} / \mathrm{mol}$ smaller than the more crowded $\mathbf{T S}_{\mathbf{1 / 2}} \mathbf{- B}$; see Figure 3. This calculation result is consistent with Harada's work that a chiral product [4] was obtained in the Strecker reaction.

\section{Hydrolysis of amino nitrile to amino acid (the second stage)}

In the acidic hydrolysis of amino nitrile, we take 2-aminopropanonitrile $+\mathrm{H}_{3} \mathrm{O}^{+}\left(\mathrm{H}_{2} \mathrm{O}\right)_{10}(\mathbf{8})$ as a precursor complex; see Figure S3 in Supporting Information File 1 for the geometry of 8. Our proposed pathways are shown in Scheme 8.

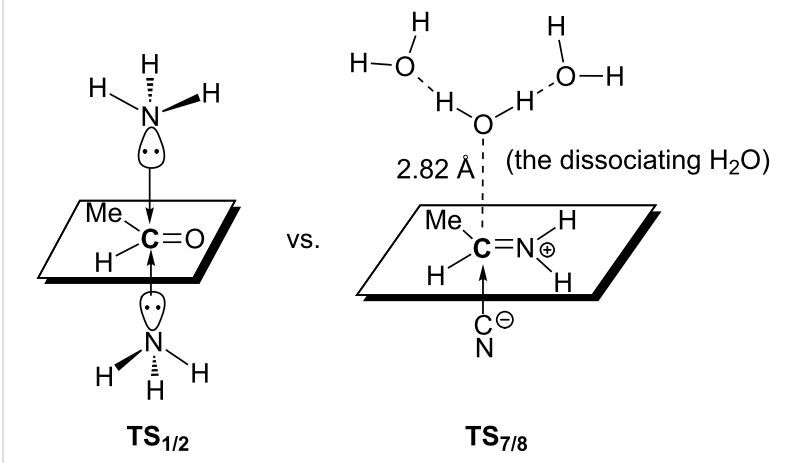

both additions are equivalent

Scheme 7: A contrast of the nucleophilic addition.

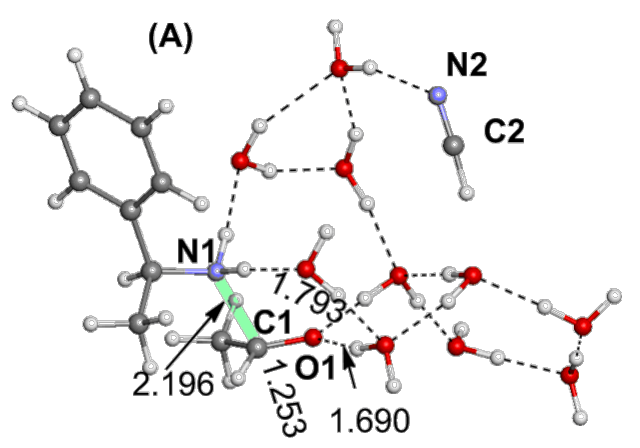

$v^{\neq}=84.10 \mathrm{icm}^{-1}$

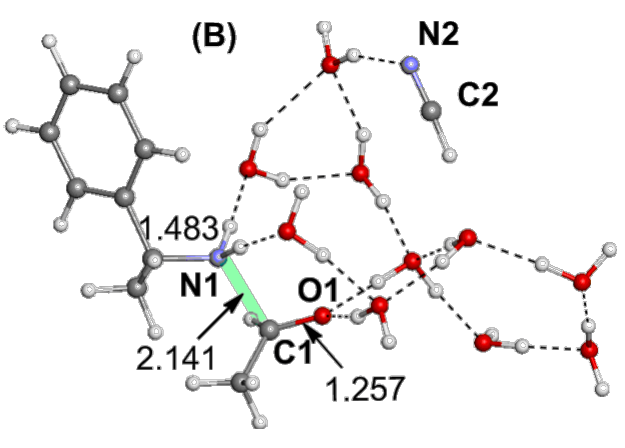

$v^{\neq}=101.98 \mathrm{icm}^{-1}$

Figure 3: Two transition states $(\mathrm{A}$ and $\mathrm{B})$ of the nucleophilic addition of $(\mathrm{S})$ - $\alpha$-phenylethylamine to acetaldehyde. $\left(\mathrm{H}_{2} \mathrm{O}\right)_{10}$ is also included, and the molecular formula of the reaction system is $\mathrm{C}_{11} \mathrm{H}_{36} \mathrm{~N}_{2} \mathrm{O}_{11}$. 
Pathway I

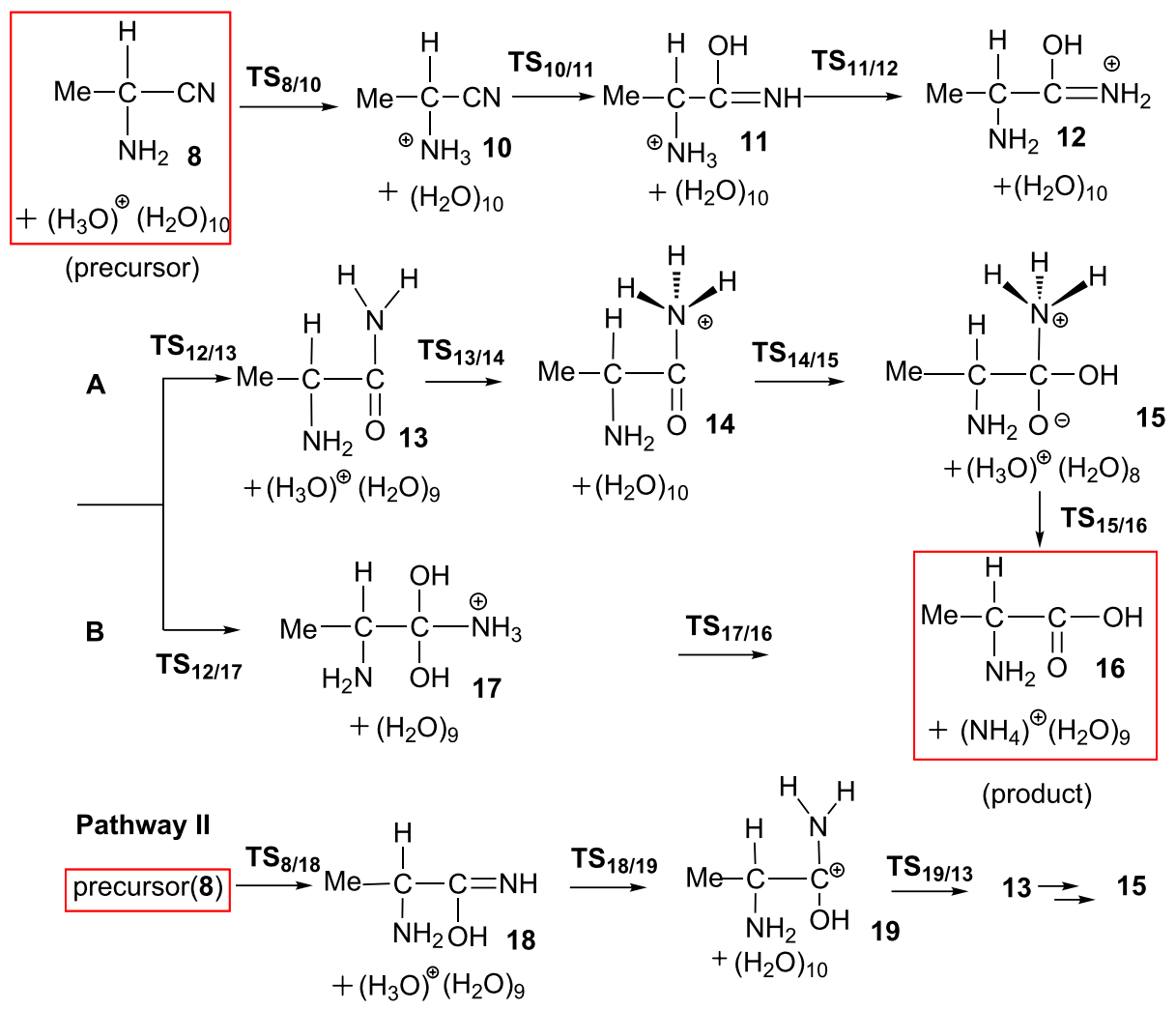

Scheme 8: Elementary processes of the acid-catalyzed hydrolysis of 2-amino-propanonitrile.

There are two competitive pathways from the precursor complex: One (I) is the protonation of the amino group to form a $\mathrm{N}$ (on amino)-protonated aminonitrile 10. This step occurs through $\mathbf{T S}_{\mathbf{8} / 10}$ with the $\Delta E^{f}$ and $\Delta E$ values of 4.1 and -6.8 $\mathrm{kcal} / \mathrm{mol}$, respectively; see Figure 4 .

The other pathway (II) is the hydrolysis of the $\mathrm{C} \equiv \mathrm{N}$ group to form a compound $\mathbf{1 8}$ through $\mathbf{T S} \mathbf{S}_{\mathbf{8} / \mathbf{1 8}}$, where the $\mathrm{OH}$ group is added to the carbon atom and the hydrogen atom attachs to the nitrogen atom. This step needs a considerably large energy barrier of $32.0 \mathrm{kcal} / \mathrm{mol}$ with an endothermicity of $0.2 \mathrm{kcal} / \mathrm{mol}$. Obviously, the protonation of the amino group (I) is much more favorable than the hydrolysis of the cyano group (II). As a result, compound $\mathbf{1 0}$ is the starting point for the following reactions. From 10, a water trimer reacts with the cyano group through $\mathbf{T S}_{\mathbf{1 0} / \mathbf{1 1}}$ to afford the N(on amino)-protonated 2-amino1-hydroxypropanimine $\mathbf{1 1}$. At $\mathbf{T S}_{\mathbf{1 0} / \mathbf{1 1}}$, the hydroxy group adds to the carbon atom of the cyano carbon nucleophilically. Simultaneously, the proton migrates to the nitrogen atom through a two-water-bridge; see Figure 5 for the geometry of $\mathbf{T S}_{\mathbf{1 0} / \mathbf{1 1}}$. The $\mathrm{C} \equiv \mathrm{N}$ group in $\mathbf{1 0}$ convers to a $\mathrm{C}(\mathrm{OH})=\mathrm{NH}$ group in $\mathbf{1 1}$. This reaction step is endothermic by $4.6=[-2.2-(-6.8)] \mathrm{kcal} / \mathrm{mol}$ with a large $\Delta E^{\neq}$value of $34.7=[+27.9-(-6.8)] \mathrm{kcal} / \mathrm{mol}$. Although this $\Delta E^{\neq}$value is apparently larger than that of $\mathbf{T S}_{\mathbf{8} / \mathbf{1 8}}$, $\mathbf{T S}_{\mathbf{1 0} / 11}$ lies lower than $\mathbf{T S}_{\mathbf{8} / \mathbf{1 8}}$ by $4.1 \mathrm{kcal} / \mathrm{mol}$ when taking the energy of the precursor complex as a reference; see Figure 4. We examined the role of the $\mathrm{NH}_{3}{ }^{+}$group in the reaction by investigating the hydrolysis of the cyano group of a methylsubstituted model 10(Me). In this model, we replaced the $\mathrm{NH}_{3}{ }^{+}$ group in $\mathbf{1 0}$ with a methyl group. The $\Delta E^{\ddagger}$ value of the hydrolysis step increases to $34.6 \mathrm{kcal} / \mathrm{mol}$. It indicates that the $\mathrm{NH}_{3}{ }^{+}$ group enhances the electrophilicity of the cyano carbon, which is favorable for the $\mathrm{OH}_{2}$ addition. The TS geometry of the methyl substituted model, $\mathbf{T S}_{\mathbf{1 0} / \mathbf{1 1}}(\mathrm{Me})$, is shown in Supporting Information File 1 Figure S6.

In the following, a proton on the $\mathrm{NH}_{3}{ }^{+}$group in $\mathbf{1 1}$ is transferred to the imine nitrogen to afford $\mathbf{1 2}$. This proton transfer step is facilitated by a water molecule bridge. The $\Delta E^{f}$ and $\Delta E$ values are $5.5=[+3.3-(-2.2)]$ and $-3.8=[-6.0-(2.2)] \mathrm{kcal} /$ mol, respectively. Starting from 12, there are two possible pathways, paths $\mathbf{A}$ and $\mathbf{B}$, to form the final alanine product; see Scheme 8. In path $\mathbf{A}$, the deprotonation of the amino group occurs to produce an amide intermediate $\mathbf{1 3}$ with an exother- 


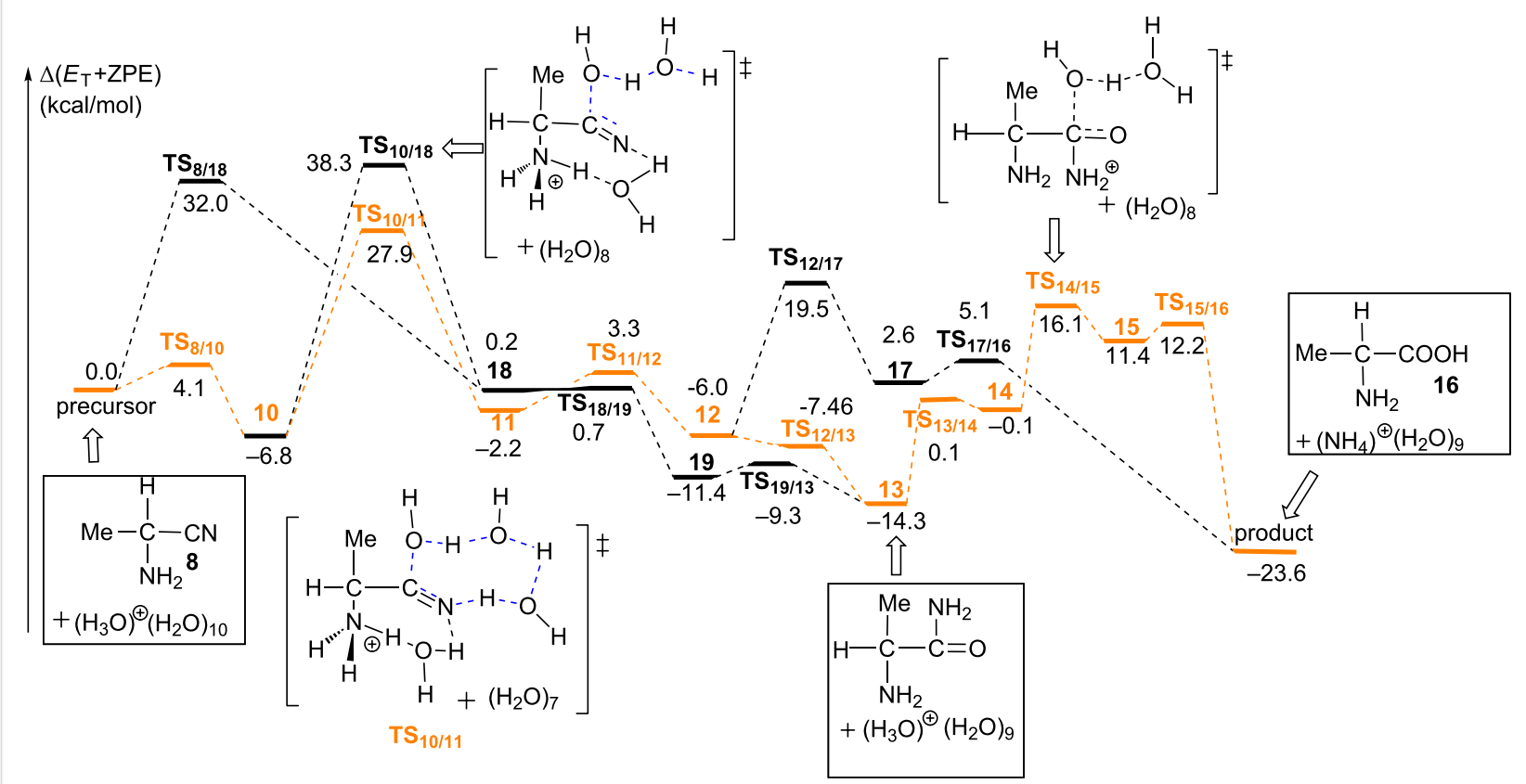

Figure 4: Energy changes along elementary processes from 2-amino nitrile $\mathbf{8}$ to 2-amino acid $\mathbf{1 6}$. Brown-color lines stand for the most favorable route.

micity of $-8.3=[-14.3-(-6.0)] \mathrm{kcal} / \mathrm{mol}$; see Figure 4 . In the following, the protonation of the amide nitrogen atom occurs to produce a cationic species $\mathrm{MeC}\left(\mathrm{NH}_{2}\right) \mathrm{H}-\mathrm{C}(=\mathrm{O})-\mathrm{NH}_{3}{ }^{+}$14. The amide carbon in $\mathbf{1 4}$ is subject to the $\mathrm{OH}_{2}$ addition to afford a zwitterion compound $\mathrm{MeC}\left(\mathrm{NH}_{2}\right) \mathrm{H}-\mathrm{C}(\mathrm{OH})\left(\mathrm{O}^{-}\right)-\mathrm{NH}_{3}{ }^{+} \mathbf{1 5}$. The $\Delta E^{\neq}$and $\Delta E$ values of the $\mathrm{H}_{2} \mathrm{O}$ addition step relative to the

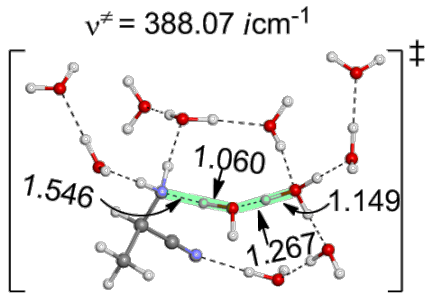

$\mathrm{TS}_{8 / 10}$

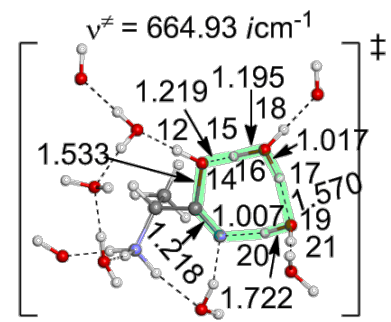

$\mathrm{TS}_{10 / 11}$

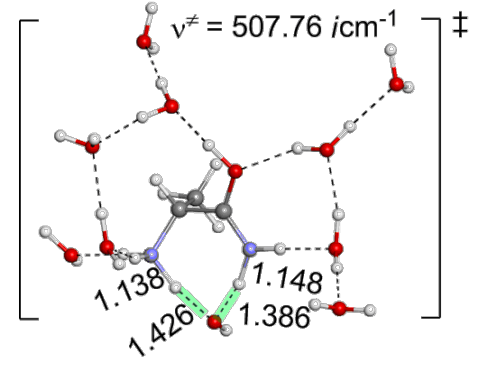

$\mathrm{TS}_{11 / 12}$

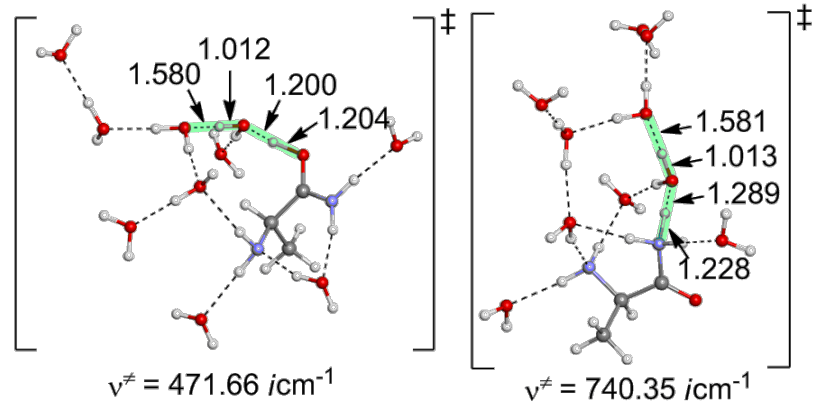

$\mathrm{TS}_{12 / 13}$

$\mathrm{TS}_{13 / 14}$

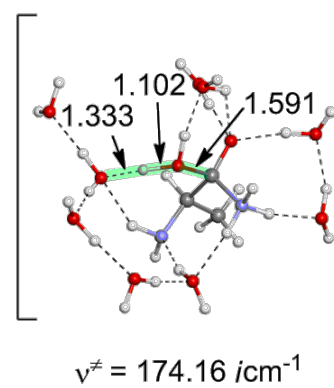

$\mathrm{TS}_{14 / 15}$

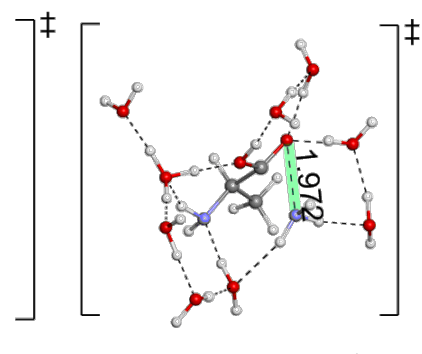

$v^{\neq}=227.69 \mathrm{icm}^{-1}$

$\mathrm{TS}_{15 / 16}$

Figure 5: Geometries of transition states along the most favorable route from 2-aminonitrile 8 to 2-amino acid 16. 
energy of $\mathbf{1 3}$ are 30.5 and $25.8 \mathrm{kcal} / \mathrm{mol}$, respectively. After that, the $\mathrm{NH}_{3}$ moiety is ready to dissociate from $\mathbf{1 5}$ to produce the product $(R)$-alanine 16 with a $\Delta E^{\neq}$value of $0.7 \mathrm{kcal} / \mathrm{mol}$ of $\mathbf{T S}_{\mathbf{1 5} / \mathbf{1 6}}$. In path $\mathbf{B}$, the second $\mathrm{H}_{2} \mathrm{O}$ molecule is added to the $\mathrm{C}=\mathrm{N}$ double bond in $\mathbf{1 2}$ to form an intermediate $\mathbf{1 7}$ through $\mathbf{T S}_{\mathbf{1 2} / \mathbf{1 7}}$. The $\Delta E^{\neq}$and $\Delta E$ values of this step are 25.5 and 8.6 $\mathrm{kcal} / \mathrm{mol}$, respectively. However, $\mathbf{T S}_{\mathbf{1 2} / \mathbf{1 7}}$ lies higher than $\mathbf{T S}_{\mathbf{1 4} / \mathbf{1 5}}$ by $3.1 \mathrm{kcal} / \mathrm{mol}$ and $\mathbf{1 7}$ in path $\mathbf{B}$ is much more unstable than the intermediate $\mathbf{1 3}$ in path $\mathbf{A}$ by $17.0 \mathrm{kcal} / \mathrm{mol}$. These energy differences suggest that the deprotonation of the amino group occurs more favorably. Then, from 17 the elimination of the $\mathrm{NH}_{4}^{+}$group takes place to afford the alanine $\mathbf{1 6}$ with a $\Delta E^{\neq}$ value of $2.5 \mathrm{kcal} / \mathrm{mol}$. According to the above discussion, the path-B is less favorable than the path $\mathbf{A}$.

The most favorable pathway for the second stage of the Strecker reaction was shown in brown color in Figure 4. The rate-determining step is the $\mathrm{OH}_{2}$ addition to the cyano group $\left(\mathbf{T S}_{\mathbf{1 0} / \mathbf{1 1}}\right)$ with the activation energy of $27.9 \mathrm{kcal} / \mathrm{mol}$. The competitive $\mathbf{T S}_{\mathbf{8} / \mathbf{1 8}}$ has an energy barrier of $32.0 \mathrm{kcal} / \mathrm{mol}$. Geometries along the unfavorable routes pathway II and pathway IB, are shown in Figures S4 and S5, Supporting Information File 1, respectively. The relative stability of these two transition states were checked with extended models $\mathbf{T S}_{\mathbf{1 0} / \mathbf{1 1}}$-ext and $\mathbf{T S}_{\mathbf{8} / \mathbf{1 8}}$-ext, which have a molecular formula of $\mathrm{C}_{3} \mathrm{H}_{49} \mathrm{~N}_{2} \mathrm{O}_{21}{ }^{+}$. Their geometries are shown in Figure S7. $\mathbf{T S}_{\mathbf{8} / \mathbf{1 8}}$-ext lies higher than TS $_{10 / 11}$-ext by $3.4 \mathrm{kcal} / \mathrm{mol}$, which is consistent with the small model system.

\section{Conclusion}

In this work, we theoretically investigated the whole Strecker reaction shown in Scheme 1(a), which includes two reaction stages. The most favorable pathways are summarized in Scheme 9.

As shown in the upper half of Scheme 9, the first reaction stage, acetaldehyde $+\mathrm{NH}_{3}+\mathrm{HCN}+\left(\mathrm{H}_{2} \mathrm{O}\right)_{10}(\mathbf{1}) \rightarrow$-aminopropanonitrile $\left(\mathrm{H}_{2} \mathrm{O}\right)_{11}(\mathbf{8})$, is composed of seven elementary processes. The rate-determining step is the deprotonation of the $\mathrm{NH}_{3}{ }^{+}$group in $\mathrm{MeCH}(\mathrm{OH})-\mathrm{NH}_{3}{ }^{+}$to form 1-aminoethanol, which occurs with an activation energy barrier of $9.6 \mathrm{kcal} / \mathrm{mol}$. The stereochemistry ( $R$ or $S$ ) of the product aminonitrile is determined by equal addition of $\mathrm{NH}_{3}$ to the carbonyl carbon of the aldehyde in both sides. While the addition of $\mathrm{CN}^{-}$to the carbon atom of the protonated imine 7 appears to give the scrambling of the stereochemistry, the water cluster above the imine plane reinforces the $\mathrm{CN}^{-}$to attack the carbon atom below the plane; see Scheme 7. While $\mathrm{HCN}$ is a very weak acid, $\mathrm{CN}^{-}$ may be generated by the proton transfer, $\mathrm{HCN}+\mathrm{OH}^{-} \rightarrow \mathrm{CN}^{-}+$ $\mathrm{H}_{2} \mathrm{O}\left(\mathbf{3} \rightarrow \mathbf{T S}_{\mathbf{3} / \mathbf{4}} \rightarrow \mathbf{4}\right)$ in this reaction stage. As shown in the

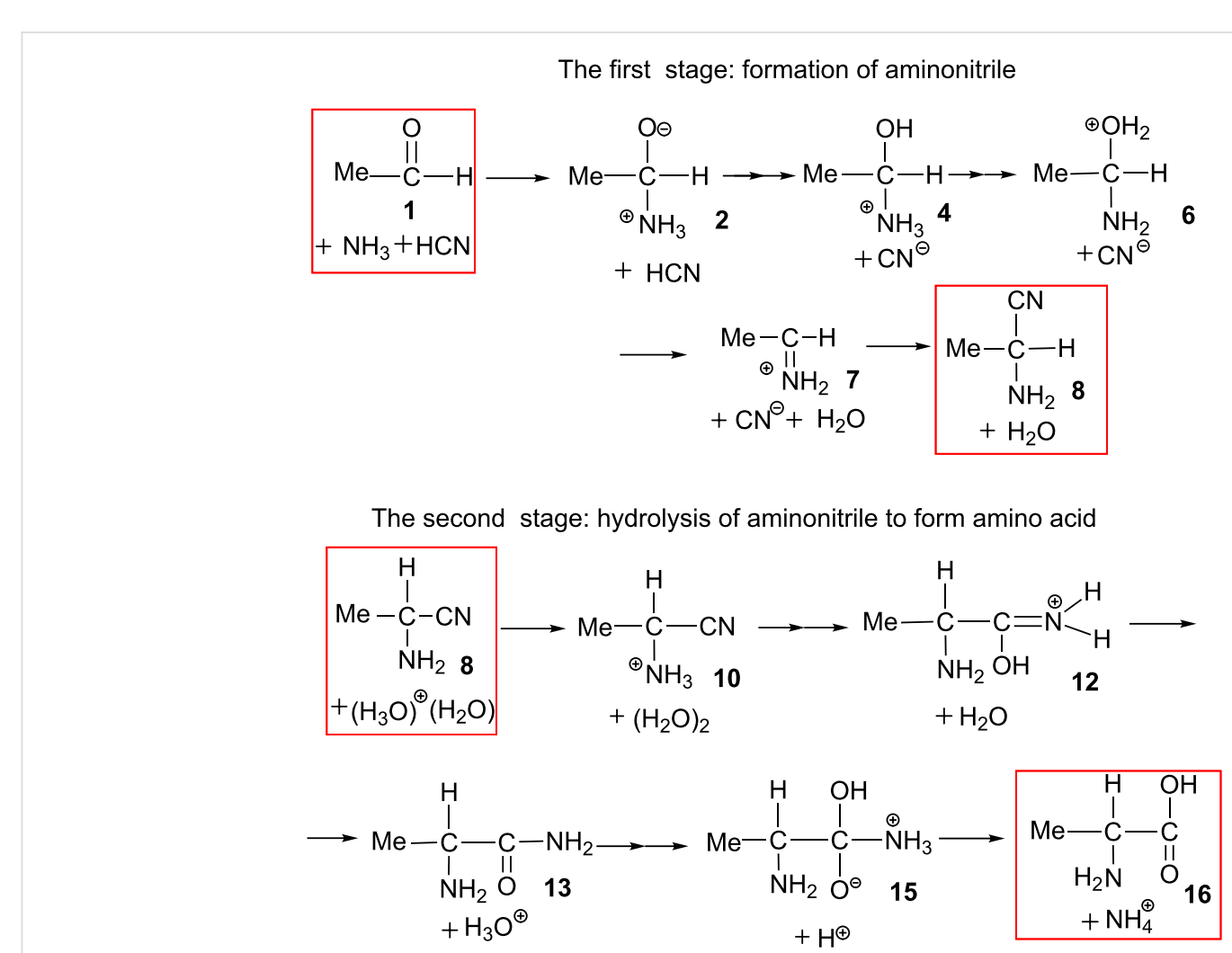


lower half of Scheme 9, the second reaction stage, aminonitrile $+\mathrm{H}_{3} \mathrm{O}^{+}\left(\mathrm{H}_{2} \mathrm{O}\right)_{10} \rightarrow$ alanine $+\mathrm{NH}_{4}^{+}\left(\mathrm{H}_{2} \mathrm{O}\right)_{9}$, is also composed of seven elementary processes. In this reaction stage, the protonation to the amino nitrogen occurs first, which enhances the subsequent hydrolysis of the cyano group to form an imine $\mathrm{C}(\mathrm{OH})=\mathrm{NH}$ moiety. Its rate-determining step is the hydrolysis of the cyano group of $\mathrm{N}$ (amino)-protonated aminonitrile to afford a N(amino)-protonated 1-hydroxypropanimine 11. The $\Delta E^{\neq}$value of this step is $34.7 \mathrm{kcal} / \mathrm{mol}$ and the large value corresponds to the high temperature conditions in Scheme 1(b).

\section{Supporting Information}

Suppoting Information File 1:

\section{Supporting Information File 1}

File Format: PDF.

Cartesian coordinates of optimized geometries in Figures 1, 3 , and 6 and Figures S1-S7.

[http://www.beilstein-journals.org/bjoc/content/ supplementary/1860-5397-10-184-S1.pdf]

\section{Acknowledgements}

This work is financially supported by the Grants-in-Aid from the Ministry of Education, Culture, Science, Sport, and Technology through Grants-in-Aid of Specially Promoted Science and Technology (No. 22000009) and Grand Challenge Project (IMS, Okazaki, Japan). We are also thankful to the computational facility at the Institute of Molecular Science, Okazaki, Japan.

\section{References}

1. Strecker, A. Justus Liebigs Ann. Chem. 1850, 75, 27-45. doi:10.1002/jlac. 18500750103

2. Cram, D. J.; Hammond, G. S. Organic Chemistry, 2nd ed.; McGraw-Hill: New York, 1964; pp $306 \mathrm{ff}$.

3. Kendall, E. C.; McKenzie, B. F.; Tobie, W. C.; Ayres, G. B. Org. Synth. 1929, 9, 4.

4. Harada, K. Nature 1963, 200, 1200-1201. doi:10.1038/2001201a0

5. Iyer, M. S.; Gigstad, K. M.; Namdev, N. D.; Lipton, M. J. Am. Chem. Soc. 1996, 118, 4910-4911. doi:10.1021/ja952686e

6. Sigman, M. S.; Jacobsen, E. N. J. Am. Chem. Soc. 1998, 120, 4901-4902. doi:10.1021/ja980139y

7. Sigman, M. S.; Jacobsen, E. N. J. Am. Chem. Soc. 1998, 120, 5315-5316. doi:10.1021/ja980299+

8. Sigman, M. S.; Vachal, P.; Jacobsen, E. N. Angew. Chem., Int. Ed. 2000, 39, 1279-1281. doi:10.1002/(SICI)1521-3773(20000403)39:7<1279::AID-ANIE1279>3. $0 . \mathrm{CO} ; 2-\mathrm{U}$

9. Vachal, P.; Jacobsen, E. N. Org. Lett. 2000, 2, 867-870. doi:10.1021/ol005636+

10. Vachal, P.; Jacobsen, E. N. J. Am. Chem. Soc. 2002, 124, 10012-10014. doi:10.1021/ja027246j
11. Zuend, S. J.; Coughlin, M. P.; Lalonde, M. P.; Jacobsen, E. N. Nature 2009, 461, 968-970. doi:10.1038/nature08484

12. Zuend, S. J.; Jacobsen, E. N. J. Am. Chem. Soc. 2009, 131, 15358-15374. doi:10.1021/ja9058958

13. Arnaud, R.; Adamo, C.; Cossi, M.; Milet, A. Y. V.; Barone, V. J. Am. Chem. Soc. 2000, 122, 324-330. doi:10.1021/ja9911059

14. Kitayama, T.; Watanabe, T.; Takahashi, O.; Morihashi, K.; Kikuchi, O. J. Mol. Struct.: THEOCHEM 2002, 584, 89-94. doi:10.1016/S0166-1280(02)00023-4

15. Li, J.; Han, K.-L.; He, G.-Z.; Li, C. J. Org. Chem. 2003, 68, 8786-8789. doi:10.1021/jo034891f

16. Li, J.; Han, K.-L.; He, G.-Z. J. Mol. Struct.: THEOCHEM 2005, 713, 51-57. doi:10.1016/j.theochem.2004.09.054

17. Becke, A. D. J. Chem. Phys. 1993, 98, 5648-5652. doi:10.1063/1.464913

18. Lee, C.; Yang, W.; Parr, R. G. Phys. Rev. B 1988, 37, 785-789. doi:10.1103/PhysRevB.37.785

19. Cancès, E.; Mennucci, B.; Tomasi, J. J. Chem. Phys. 1997, 107, 3032-3041. doi:10.1063/1.474659

20. Cossi, M.; Barone, V.; Mennucci, B.; Tomasi, J. Chem. Phys. Lett. 1998, 286, 253-260. doi:10.1016/S0009-2614(98)00106-7

21. Mennucci, B.; Tomasi, J. J. Chem. Phys. 1997, 106, 5151-5158. doi:10.1063/1.473558

22. Fukui, K. J. Phys. Chem. 1970, 74, 4161-4163. doi:10.1021/j100717a029

23. Gonzalez, C.; Schlegel, H. B. J. Chem. Phys. 1989, 90, 2154-2161. doi:10.1063/1.456010

24. Gaussian 09, Revision B.01; Gaussian, Inc.: Wallingford CT, 2010.

25. Yamabe, S.; Guan, W.; Sakaki, S. Beilstein J. Org. Chem. 2013, 9 , 185-196. doi:10.3762/bjoc.9.22

26. Yamabe, S.; Zeng, G.; Guan, W.; Sakaki, S. Beilstein J. Org. Chem. 2013, 9, 1073-1082. doi:10.3762/bjoc.9.119

\section{License and Terms}

This is an Open Access article under the terms of the Creative Commons Attribution License (http://creativecommons.org/licenses/by/2.0), which permits unrestricted use, distribution, and reproduction in any medium, provided the original work is properly cited.

The license is subject to the Beilstein Journal of Organic Chemistry terms and conditions:

(http://www.beilstein-journals.org/bjoc)

The definitive version of this article is the electronic one which can be found at: doi:10.3762/bjoc. 10.184 